\title{
Globalización del proceso productivo en el sector cooperativo: el caso de Erreka Mex
}

\author{
Paula Arzadun \\ Escuela de Administración de Empresas \\ TEC - Tecnológico de Costa Rica \\ Cartago, Costa Rica
}

Sumario: 1. Introducción. 2. Globalización del proceso productivo la producción. 3. Globalización económica en el sector cooperativo. 4. El caso de Erreka Mex. 5. Discusión. 6. Referencias bibliográficas.

Resumen: Erreka forma parte de MONDRAGON, el mayor grupo empresarial de la Economía Social española. Su incursión en México inició en el año 2001. El presente artículo evalúa el impacto de la globalización de su proceso productivo establecido, combinando dos medidas: el impacto económico a través de las Tablas Input - Output, y el grado en el que se alinean las políticas y prácticas económicas, ambientales y socialmente responsables con la estrategia empresarial, para lo cual se llevó a cabo un trabajo de campo in situ. Dada la composición de su gasto intersectorial e interno, el impacto indirecto supera al inducido, lo cual muestra el mayor peso relativo por el incremento de la renta.

Palabras clave: matriz insumo-producto, globalización económica, MONDRAGON, cooperativismo, responsabilidad social empresarial.

Claves ECONLIT: F620, F610, F630, M140, L240

Abstract: Erreka Mex is part of MONDRAGON, the largest business group in the Spanish Social Economy. Its foray into Mexico began in 2001. This article evaluates the socioeconomic impact of the experience of the globalization of its established production process. The evaluation combines two measures: the economic impact through the Input - Output Tables, and the degree to which economic, environmental and socially responsible policies and practices are aligned with the business strategy. Given the composition of intersectoral and internal expenditure of Erreka Mex, the indirect impact exceeds the induced, which shows the greater relative weight product of the increase in income.

Keywords: input-output matrix, economic globalization, MONDRAGON, cooperativism, corporate social responsibility 


\section{Introducción}

MONDRAGON surgió en el año 1955. A cierre del año 2017 empleaba a 80.819 personas en sus 266 entidades, de las cuales 98 son cooperativas, ubicadas en los cinco continentes. Es el primer grupo empresarial en la Comunidad Autónoma del País Vasco, décimo a nivel del Estado Español y primero del sector de la Economía Social (MONDRAGON, 2018).

Ante la evolución, complejidad y globalización de los mercados, MONDRAGON ha buscado adaptarse y dar respuesta a un escenario en expansión, siendo uno de los efectos directos la diseminación de implantaciones productivas o experiencias de globalización del proceso productivo establecido - GPPE. A finales del año 2017, éstas sumaban 143 casos, las ventas internacionales alcanzaban el 69\% sobre las ventas totales del área industrial, y los puestos de trabajo en el ámbito internacional de dicha área industrial representaban más del $36 \%$ sobre el total, empleando de forma directa a más de 13.525 personas.

Ahora bien, ¿cómo impacta la globalización del proceso productivo establecido de MONDRAGON, entendiendo el impacto tanto en términos estrictamente económicos como en términos socioeconómicos a partir de estrategias socialmente responsables? El trabajo que aquí se presenta pretende responder esa pregunta, y es fruto de una investigación más amplia en la que se desarrolló una herramienta analítica de evaluación del impacto socioeconómico (Arzadun, 2012). Lo anterior, combinando dos medidas. Por un lado, el impacto económico a través de tablas input-output (Leontief, 1970). Por el otro, evaluando el grado en el que se alinean diversas políticas y prácticas económicas, ambientales y socialmente responsables con la estrategia empresarial (Porter y Kramer, 2006). En concreto, aquí se presenta el caso de Erreka Mex, para lo cual se llevó a cabo un trabajo de campo in situ durante el mes de junio de 2010 en Querétaro, México.

Si bien existen estudios relativos al rol de la empresa en la generación de puestos de trabajo e ingresos (Karnani, 2007; Kosacoff, 2009; Llamosas Trápaga, 2018; Salazar-Xirinachs, 2009; Somavia, 1999), estos aspectos parecen haber sido menos explorados en el ámbito cooperativo y más específicamente en torno a MONDRAGON. Más aún, en concreto respecto al modelo Input - Output o Modelo de Insumo - Producto (Leontief, 1970) que aquí se implementa, se reconoce la exigua aportación científica en esta materia dentro del ámbito del sector cooperativo e incluso algunos autores que lo han 
hecho reconocen esta carencia (Deller et al., 2009). De esta forma, el presente trabajo pretende generar aportes en relación a los vacíos mencionados.

\section{Globalización del proceso productivo}

El presente trabajo se centra en la dimensión económica de la globalización (Fonseca y Martínez Gonzáles-Tablas, 2008), y más concretamente en lo concerniente al proceso productivo. Al respecto, se han desarrollado aportaciones teóricas y empíricas principalmente en dos líneas: en torno a transnacionalización productiva y a inversión extranjera directa - IED.

En cuanto a la transnacionalización productiva, se caracteriza por una localización dispersa a nivel mundial de las diversas actividades que realiza internamente la empresa, es decir las distintas etapas de su cadena de valor, de modo tal de ofrecer bienes y servicios al mercado global. Vale indicar que la transnacionalización de la empresa se trata de una variante de globalización productiva que ocurre sin la presencia de inversiones directas siendo ello posible, a modo de ejemplo, por medio de alianzas estratégicas, licencias, franquicias, etc. (Martínez González-Tablas, 2004; Oficina Internacional de Trabajo - OIT, 1998), o por medio de contrataciones externas. «Paradójicamente, la integración creciente de los mercados, derivada de la globalización, ha traído consigo la desintegración del proceso productivo, en el que las actividades de producción de bienes y servicios realizadas en terceros países se combinan con las que son realizadas en cada país» (de la Dehesa, 2000, p.69).

Así, incrementalmente se da el fenómeno de empresas sin fábricas, que sustentan su permanencia en el mercado sobre la base de contrataciones externas. Este hecho se asocia al proceso de outsourcing empresarial, el cual se caracteriza por relocalizar la producción de bienes, o parte de ellos, o la oferta de servicios. El cambio más importante que se ha presentado en este proceso en las últimas décadas es la emergencia del outsourcing entre naciones. Se destacan dos tipologías: por un lado, la transferencia de operaciones funcionales, como por ejemplo la relocalización de centros telefónicos de atención al cliente, de actividades comerciales, diseño, control de calidad; y por el otro, la contratación indirecta de trabajo (Ohmae, 2005) para la compra de bienes finales o intermedios. Otros autores, como Cadarso Vecina et al. (2007), realizan una diferenciación entre outsourcing intra e inter industrial: 
— Intra-industrial: se refiere a la compra de bienes intermedios o actividades de servicio muy próximos a la producción principal de la empresa. En otras palabras, se trata de la externalización de actividades que se realizaban previamente en la organización. Básicamente esta transnacionalización productiva se presenta porque los beneficios del costo de producción superan los costos de transacción que generan;

- Inter-industrial: se refiere a la compra de bienes intermedios que proceden de otros sectores de la economía.

La fragmentación productiva da lugar a un proceso de especialización vertical en la que diferentes países se especializan en distintas fases de la cadena de valor o, en otras palabras, a una creciente interconexión de las actividades productivas entre diferentes países (Rubert Adelantado y Uribe-Echeverría, 2002; Tugores Ques, 2006). Ello representa un radical cambio de las tradicionales formas de producción integradas verticalmente al interior de las empresas.

De acuerdo con el Comité Económico y Social Europeo - CESE (2005) estos fenómenos acarrean un proceso de desindustrialización, distinguiendo dos posibles resultados:

- Desindustrialización absoluta: conlleva una reducción de puestos de trabajo, de la producción, de la rentabilidad y de la masa de capital en la industria. Asimismo, provoca un declive de las exportaciones de bienes industriales, lo cual es acompañado por déficit comerciales persistentes en este sector;

- Desindustrialización relativa: producto de un proceso de cambio estructural en lo referente a la relación entre la productividad de la industria y el sector de servicios, consiste en la reducción de la cuota de la industria en la economía.

Entonces, en función de la proporción que represente la transnacionalización productiva sobre el total de las actividades emprendidas por la empresa, ésta incidirá relativa o absolutamente en la desindustrialización de la economía desde donde se origina tal transferencia intra-industrial.

Ante esta situación, los principales efectos negativos identificados por el CESE (2005) para la economía de origen son cuatro: (1) la pérdida de competitividad; (2) la menor generación de conocimientos; (3) la pérdida de puestos de trabajo y el empeoramiento de las oportunidades en el mercado de trabajo; (4) el menor crecimiento de la economía, proponiendo mitigar tales efectos principalmente me- 
diante la adopción de medidas ${ }^{1}$ sociales, económicas y formativas que favorezcan la generación de riqueza, bienestar y empleo.

Sin embargo, es preciso no sólo evaluar los resultados indeseados en el país que origina la transnacionalización productiva, sino aquellos que acontecen en la economía receptora siendo que pueden incidir negativamente tanto en las cuatro dimensiones mencionadas como también en otros aspectos sociales, económicos y medioambientales del corto y largo plazo. En este sentido, mucho se ha debatido sobre los supuestos beneficios mutuos entre países en situaciones en las cuales las economías en riesgo inician actividades en segmentos de menor calidad y con productos estandarizados, que pueden ser ofrecidos a menor precio porque sus factores de producción así lo permiten, mientras que las economías desarrolladas abandonan estos segmentos de mercado para avanzar en otros de mayor nivel agregado (Frank, 1974; Hirschman, 1980; Myrdal, 1957; Stiglitz, 2002). Estos círculos virtuosos parecen no ser automáticos, ni conducir necesariamente de manera espontánea al desarrollo global. Por ello, en aras de una conducción socialmente responsable de las transnacionalizaciones productivas es preciso efectuar una lectura global de las consecuencias generadas.

Respecto a las IED, la segunda línea en la que se han desarrollado aportaciones teóricas y empíricas en materia de globalización del proceso productivo, ésta permite la creación, ampliación o control de empresas que ejercen su actividad fuera del territorio de la economía desde donde se origina, a diferencia de las inversiones en cartera o financieras. El propósito de las IED consiste, entonces, en la producción de bienes y prestación de servicios en el país receptor, para lo cual se crean y gestionan empresas (Adda, 1999; Martínez González-Tablas, 2004). Pero ello no se trata sólo de transferencia de capital sino de conocimiento sobre gestión y saberes técnicos (García Zabala, 2005), además de la adquisición del control (Krugman y Obstfeld, 1999). Vale mencionar que la toma de control puede no suponer una aportación de capital (Adda, 1999).

A lo largo de la historia se han desarrollado diferentes teorías procurando explicar las IED, tales como el modelo neoclásico, la teoría ecléctica o paradigma OLI, la determinación endógena, y la teoría de la competencia monopolística.

1 Específicamente se proponen ocho medidas vinculadas a: educación, formación y cualificación; investigación e innovación; la mejora del entorno normativo; una mayor cooperación público - privada en sectores claves para acelerar el desarrollo, inversión en infraestructuras; fomento al espíritu empresarial; diálogo social entre actores afectados y cooperación internacional (CESE, 2005). 
El modelo neoclásico cuenta como mayores exponentes a Solow (1956) y Swan (1956). Sobre la base de los previos desarrollos del modelo Harrod-Domar (Harrod, 1939) admite el carácter sustituible de factores frente a la relación capital-producto exógena de Harrod-Domar. De esta forma, se propone una función de producción en la que el output obtenido es resultado de la aplicación de capital y trabajo, combinados con la tecnología disponible y según los precios de los factores que rigen en el mercado. Se supone el rendimiento constante de escala y el rendimiento marginal decreciente para cada factor. El modelo de Solow loga brindar una fundamentación microeconómica más acabada respecto a los aportes previos, concretando el nivel de renta per cápita de equilibrio en función de la propensión a ahorrar, de la tasa de crecimiento demográfica y de la tasa de amortización. Así mismo, permite derivar los condicionantes del crecimiento, los cuales están representados por tres factores: el incremento de las horas trabajadas, el crecimiento del volumen de capital productivo y la tasa de progreso técnico. Al aplicar este procedimiento a diferentes países, se revela cuáles han sido los factores que traccionaron su crecimiento (Alonso y Donoso, 1994).

Sin embargo, a pesar de las ventajas reseñadas, se observan limitaciones que pueden incluso asociarse a las de la Teoría de las Ventajas Comparativas. En este sentido, si bien se incluye la tasa de progreso técnico como un factor que condiciona al crecimiento, se trata de una variable exógena. Asimismo, se supone la existencia de rendimientos marginales decrecientes en la relación capital-trabajo. De esta forma, si el crecimiento sólo depende de la expansión del volumen de capital, nuevamente la economía atravesaría fases de estancamiento. Así, las dos variables que podrían evitarlo son la expansión demográfica o el progreso técnico, pero ambas variables son consideradas exógenas. Por lo tanto, así como el modelo ricardiano no explicita las razones que sostienen las diferencias de productividad entre naciones, este modelo elude explicar las variables vitales que explican el crecimiento (Swan, 1956). En esta misma línea, y bajo el supuesto de rendimientos marginales decrecientes de factores, el factor capital se movería desde aquellas economías en donde es abundante hacia donde escasea en términos relativos, buscando su mayor retribución. Sin embargo, se presentan inversiones entre economías intensivas en capital, lo cual no está contemplado en estos supuestos. Así es que se avanzó en el desarrollo de aportes relativos al Comercio Intraindustrial, especialmente desde la década de los setenta del siglo pasado, el cual hace referencia al comercio entre países con características similares o al comercio de bienes pertenecientes a un mismo sector (Fischer y Dornbusch, 1985; Grubel y Lloyd, 1975). 
Por su parte, la teoría ecléctica o paradigma OLI, resulta fruto de los aportes de Hymer (1976). Este trabajo significó el comienzo de la teoría entorno a la IED, entendido como el estudio del rol de las empresas en el exterior mediante la directa realización de inversiones. El autor es considerado el padre de esta teoría por haber sido la primera persona en analizar a las IED frente a otras formas de operaciones: exportaciones y licencias (Lall, 1993; Pitelis, 2006). Primeramente, diferencia las inversiones de cartera de las inversiones directas. Simplificando, podría decirse que las primeras están condicionadas por las tasas de interés y de cambio, y no suponen la toma de control. Respecto a las segundas, distingue dos tipos. En primer lugar, señala a la inversión directa (tipo 1) como aquellas «que tienen que ver con el uso prudente de los activos. El inversor busca control sobre la empresa de forma tal de asegurar la seguridad de su inversión (...) La teoría del tipo 1 inversión directa es muy similar a la teoría de inversión en portfolio. La tasa de interés es el factor clave en ambas» (Hymer, 1976, pp.23 - 24). En segundo lugar, identifica como inversión directa del tipo 2 u operaciones internacionales, a aquellas inversiones en las que el control no está motivado por el uso prudente de activos, sino para «remover competencia entre esa empresa extranjera y empresas en otros países. O el control es deseado para apropiarse completamente de los beneficios o de ciertas habilidades o capacidades (Hymer, 1976, p.25). De esta manera, y a partir del tipo 2, Hymer (1976) encuentra tres motivos, o ventajas, que estimulan a la empresa a invertir en el exterior: propiedad, localización e internacionalización. Por sus denominaciones en inglés, el paradigma toma el nombre OLI (Ownership: propiedad; Localization: localización; Internationalization: internacionalización).

En primer lugar, las ventajas de propiedad se vinculan con búsqueda de rentabilizar activos más allá de las fronteras de la empresa. Esos activos pueden ser tangibles, como por ejemplo la capacidad de producción, o intangibles, como el caso de conocimientos tecnológicos.

En segundo lugar, las ventajas de localización procuran explicar los motivos por los cuales ciertas regiones son atractivas para la implantación de empresas, así como las razones por las que determinadas zonas impulsan IED. Es decir, se intenta explicar el movimiento de las IED tanto desde el origen como desde el destino. Respecto al primero, la presencia de mercados financieros desarrollados, así como de un alto nivel tecnológico y de formación de personas parecen ser propulsores de IED. En cuanto al segundo, las causas que atraen inversiones se vinculan con temas de costos, infraestructuras, mercado y estado de derecho. 
Por último, las ventajas de internacionalización se contraponen a los costos de transacción que surgen al abastecer a un mercado foráneo por medio de licencias, ya sea por asimetría de información o por los mecanismos que tendría que implementar para minimizar tal asimetría.

De esta manera, el análisis integral de las tres ventajas identificadas por el autor y la consiguiente comparación entre las alternativas que ofrecen las exportaciones, las franquicias o licencias y las IED, se alcanza la conclusión de que son éstas últimas las que reúnen las tres ventajas.

A pesar de la capacidad explicativa de la teoría ecléctica, hay temas que no logra dilucidar como por ejemplo las integraciones horizontales o verticales de las empresas en mercados extranjeros o la relación entre costes asociados a la exportación o la inversión frente a la productividad de la empresa. La determinación endógena de la organización aborda estos aspectos. Lo que se postula es la existencia de costos adicionales asociados a la entrada de mercados exteriores tanto por medio de exportaciones como de inversiones directas. Helpman et al. (2004) plantean un análisis que contrasta los beneficios adicionales de exportar o desarrollar IED, los costes que ello supone y la productividad de la empresa. Otro elemento que toma relevancia en este análisis es la existencia de economías de escala, a las que la empresa puede renunciar al fragmentar la producción. Así, los autores llegan a la conclusión de que en los casos en donde los costes de comercio son reducidos y el potencial de las economías de escala, elevados, la exportación se convierte en la vía preferente para abordar mercados externos, mientras que las IED son oportunas en alternativas contrarias a esas.

El gráfico 1 recoge estos tres escenarios. Los beneficios asociados a vender sólo en el mercado doméstico se representan por medio de la función $\pi \mathrm{d}$. $\pi x$ muestra los beneficios adicionales de exportar. Su menor pendiente se vincula al hecho de que además de tener que incurrir en costos fijos, se debe asumir costos variables. Finalmente, los beneficios adicionales de las IED se representan por $\mathrm{mi}$, con mayores costos fijos, aunque sin los costes variables de las exportaciones.

Las empresas, cuyas productividades le permiten producir entre ad y ax se limitarán a abastecer al mercado doméstico. Aquellas que se ubican entre ax y ai encuentran en la exportación el mecanismo más adecuado. Finalmente, las más eficientes, ubicadas desde ai, podrán asumir el mayor coste generado por IED, y captar por ende su beneficio adicional. 


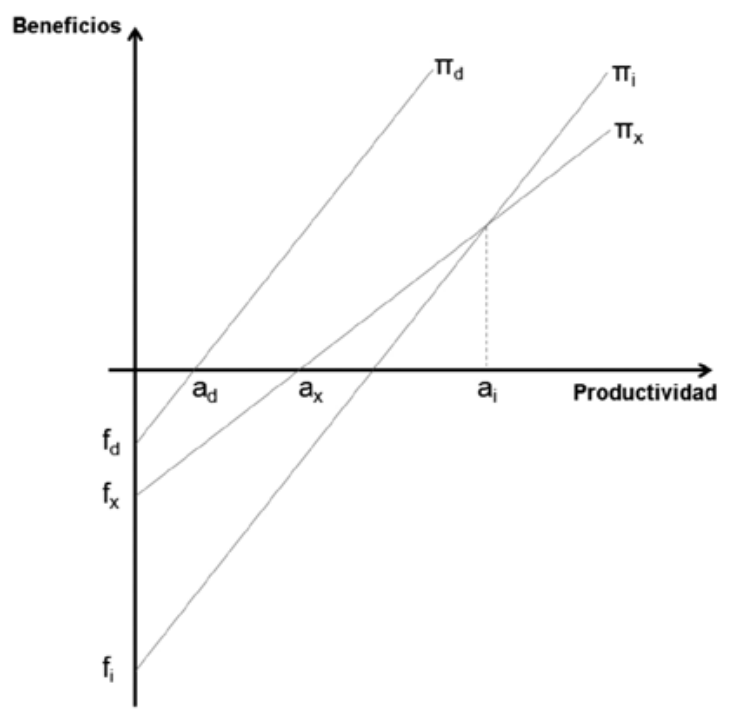

Fuente: Helpman et al (2004, p.302).

Gráfico 1. Beneficios de ventas domésticas, de exportaciones y de IED

La aplicación del modelo de competencia monopolística al comercio internacional parte del trabajo de Chamberlin (1933). Las ventajas de esta propuesta radican en su simplicidad. Se presentan dos supuestos centrales: (1) la existencia de economías de escalas internas, manteniendo fuera de actividad a la pequeña empresa, lo cual se convierte en una barrera de entrada. Por ende, (2) no es posible la existencia de competencia perfecta. Tras el primer supuesto subyace la existencia de productos diferenciados. De esta forma, cada empresa se garantiza su permanencia en el sector aislándose parcialmente de la competencia, dada la existencia de productos sustitutivos. Y por su parte, el segundo supuesto, determina que los precios están dados.

De esta forma, por medio del desarrollo de un mercado global más amplio que el doméstico, se reducirían las restricciones de variedad de bienes y se explotarían las ventajas de economías de escala. Este esquema podría impulsar relaciones intraindustriales o interindustriales en función de las similitudes o diferencias de las relaciones capital trabajo, y propulsar inversiones cruzadas de acuerdo con las barreras existentes. 
Recapitulando, y sin pretender aquí exhaustividad, se compiló principales aportes referidos a la globalización del proceso productivo en dos aristas: transnacionalización productiva e IED. Aunando el hecho de que existe una multiplicidad de conceptualizaciones con diferentes alcances y usos (Arzadun, 2012; Monzón, 2012), y que la unidad de análisis del presente trabajo no implica deslocalizaciones ni tercerizaciones productivas, se propone utilizar las nociones de:

- Globalización del proceso productivo - GPP, como concepto amplio dentro de la dimensión económica de la globalización que engloba todas aquellas actividades productivas en mercados exteriores o con mercados exteriores;

- Transnacionalización productiva, como acepción que se caracteriza por una localización dispersa a nivel mundial de las diversas actividades que realiza internamente la empresa, sin que ello suponga la existencia de inversiones directas por parte de la organización. Es decir, la actividad se desarrolla por medio de alianzas estratégicas, licencias, franquicias, contrataciones externas, sin que se presente el establecimiento propio de la empresa a nivel global.

- Globalización del proceso productivo establecido - GPPE, haciendo referencia a la existencia de empresas establecidas en el exterior, con fines productivos, e impulsadas desde una determinada empresa madre, mediando la aportación de capital y sin que implique deslocalizaciones.

De esta forma, las definiciones correspondientes a GPPE y a transnacionalización productiva quedan englobadas bajo la conceptualización de GPp. Se considera que éstas son las nociones más claras frente a las diversas concepciones y que se ajustan perfectamente a los temas aquí estudiados.

\section{Globalización económica en el sector cooperativo}

La empresa cooperativa, base del análisis del presente trabajo, se ve afectada por los retos y oportunidades generados globalmente de la misma forma en la que puede ocurrir en el resto del entramado empresarial.

Así, diversos son los provechos potenciales para la empresa cooperativa si logra posicionarse como un agente activo y protagonista en la globalización (Monzón, 2012). En primer lugar, previene la profundización de espacios de marginalización. En general el resto de las 
empresas con las que comparte mercado desarrollan estrategias para incrementar su presencia global, y si la cooperativa toma iniciativas análogas evita ser víctima de ello. En segundo lugar, reivindica los valores cooperativos de reparto de la riqueza de forma más equitativa; de una forma de empresa amplia y participativa, basada en las personas. En tercer lugar, es una vía para anular la exigua presencia en los procesos globales de transformación socioeconómica. Así, el sector cooperativo puede transmitir su forma de ser empresa. Además, para defender su lógica y valores es preciso estar presente donde el resto de organizaciones también está.

Los elementos mencionados demandan reforzar y potenciar las empresas cooperativas. "Una cooperativa debe ser, precisamente por su responsabilidad social, una empresa, y no tener vocación de subcontratista. Cuanto más potente sea la presencia de la cooperativa en el mercado más podrá defender y explicar su sistema organizativo» (De Castro Sanz, 2001, p.68). La globalización se presenta, entonces, como un desafío irrenunciable para el cooperativismo que demanda la puesta en práctica de acciones que fortalezcan al sector en cuanto a sus estructuras, representación y estrategias, de manera tal de continuar expandiendo la fórmula socioeconómica empresarial del sector cuyos fundamentos, como se mencionó precedentemente, permanecen vigentes y responden a la búsqueda de creación de empleo decente así como a estrategias socialmente responsables de las organizaciones.

Por la propia lógica de la cooperativa, es de esperar que dé respuesta a los requerimientos globales sin por ello desatender su lógica local, partiendo de los mismos retos y oportunidades que el resto del sector empresarial, aunque asentada sobre un conjunto de valores y principios propios a partir de los cuales ha de formular sus estrategias de expansión física o comercial (Arzadun, 2012; Gómez García, 2015; Izquierdo Albert, 2007). Sin embargo, aquí es donde no hay opiniones unívocas acerca de la postura de la empresa cooperativa. Es decir, si bien al repasar estudios que introducen los orígenes y valores del movimiento cooperativo se pueden identificar coincidencias entre los distintos autores, al analizar el rol de las cooperativas en la globalización económica en general y en la GPPE en particular, surgen dos posturas bien diferenciadas (Bertullo, 2007; Mendizabal y Errasti, 2006):

- La que asegura que la cooperativa es una forma colectiva y singular de organizar la empresa, por sus valores, pero que participa en el mercado como cualquier otra; 
- La que considera que el movimiento cooperativo se mantiene como una propuesta alternativa desde lo ideológico y desde lo organizativo, aspirando a un cambio social.

En concreto, esta disyuntiva supone orientarse bien a un escenario en el que prevalezca el capital sumergiendo a las filiales productivas a un espiral de regresión social, o a un escenario en el que se incite la igualdad de condiciones en todas las aristas de la actividad de la cooperativa con el objeto final de mejorar las condiciones generales de su entorno.

A esta distinción podría adicionarse una tercera, a saber: aquellos que sostienen que en los orígenes los objetivos de la cooperativa fueron mayormente claros y compartidos, pero que con el paso del tiempo se fueron tornando difusos. Dentro de este grupo, se sigue considerando a la empresa cooperativa como una entidad diferenciada del resto por sus valores, principios y aspiraciones, pero al mismo tiempo indican que en su afán de adaptarse al mercado global ha mutado en algunos de sus aspectos organizativos e ideológicos hasta tal punto que pone en riesgo la factibilidad de mantenerse apegada a esos valores, principios y aspiraciones de origen. Por ello, consideran preciso tomar conciencia de estas amenazas para actuar en consecuencia (BertuIlo, 2007; Izquierdo Albert, 2007; Kaplan de Drimer, 1996; Lara Gómez y Rico Hernández, 2007).

Las disyuntivas antes expuestas no han sido ajenas a MONDRAGON, principal grupo económico de la Economía Social española que actualmente está conformado por 266 entidades, 98 de las cuales son cooperativas, y que al cierre del 2017 empleaba a 80.818 personas alrededor del mundo (MONDRAGON, 2018). El siguiente apartado se centra en ello.

\subsection{Globalización económica de Mondragon}

Hacia los años sesenta, España comenzó a convivir en foros internacionales, entablando relaciones con el exterior y estimulando la fuerza empresarial. La globalización de MONDRAGON se remonta a estos tiempos. Ya en los años sesenta las cooperativas vieron que tenían que exportar por varias razones, siendo dos de ellas centrales: (1) tenían que buscar nuevos mercados. Ya en esos momentos comienza a tomarse conciencia de la factibilidad de otros países como mercados; (2) se empieza a pensar que lo bueno está afuera, que el conocimiento, el saber-hacer están en otros países. Surge entonces la necesidad de 
contrastar lo que se sabía contra lo que otros hacían, lo cual ayudaría a mejorar el posicionamiento competitivo. Según Herrasti (2010) «este segundo punto me parece el más importante porque se sale a buscar los mercados donde competir, optando por los más difíciles. No se conforman con lo más sencillo que hubiera sido quedarse en el ámbito de España, sino que comienzan a hacer intercambios con otros mercados, con un profundo proceso de aprendizaje y de acercamiento al mundo más competitivo».

En línea con lo antes expuesto, los motivos que impulsan la apuesta por GPPE se asientan en las necesidades de crecer, ampliando mercado y buscando espacios propios; de costos, persiguiendo la posibilidad de mantener la cartera de productos y ampliarla, buscando su rentabilidad; por petición de clientes, que demandan implantaciones cercanas a las suyas. De acuerdo con Herrasti (2010) esas son las tres razones fundamentales por las que se inició la GPPE, aunque también existen otras razones aún más sofisticadas como por ejemplo la mejora del conocimiento técnico. Esas necesidades pueden traducirse en la amenaza de desaparecer o perder posición en el mercado, no sólo porque los propios sectores impulsan la presencia global, sino porque los competidores también habían comenzado a abordar el mercado local, más aún con la inclusión de España en el Mercado Común Europeo. Las oportunidades, por su parte, no sólo se basan en la neutralización de los riesgos antes mencionados sino en las posibilidades de aprendizaje y mejora que se presentan al reconocer lo que sucede en otras empresas y mercados.

La internacionalización se estableció como uno de los objetivos básicos de MONDRAGON hacia el mes de julio de 1993, cuando se aprobó la Política Empresarial para el período 1994-1996. Ello, sumado a la «aceleración experimentada por el comercio mundial y el desarrollo creciente de los procesos de globalización, motivaron que el Consejo General celebrado en noviembre de 1994 acordara la realización de un Plan específico de Internacionalización para la Corporación» (Cancelo, 1996, p. 27) denominado Plan estratégico Corporativo de Internacionalización (PECI). Previo a tal cavilación, dos cooperativas se adelantaron a la instauración de la internacionalización como uno de los objetivos estratégicos de MONDRAGON. Producto de la reflexión que se llevó a cabo en el año 1993, se definieron tres tipos de mercados objetivo que se detallan en la tabla a continuación. 
Tabla 1

\section{Identificación de mercados objetivo por parte de Mondragon}

\begin{tabular}{|c|c|}
\hline Paises & Clasificación \\
\hline Alemania & \multirow{4}{*}{ Básic os } \\
\hline Reino Unido & \\
\hline Francia & \\
\hline Italia & \\
\hline EEUU & \multirow{8}{*}{ Prioritarios } \\
\hline Japón & \\
\hline Corea & \\
\hline China & \\
\hline Brasil & \\
\hline Canadá & \\
\hline India & \\
\hline Taiwán & \\
\hline Rusia & \multirow{11}{*}{ Potenciales } \\
\hline República Checa & \\
\hline Arabia Saudi & \\
\hline Irán & \\
\hline Argentina & \\
\hline Chile & \\
\hline Colombia & \\
\hline México & \\
\hline Dinamarca & \\
\hline Singapur & \\
\hline Hong Kong & \\
\hline
\end{tabular}

Fuente: elaboración propia a partir de Cancelo (1996).

Los años posteriores recogieron los frutos de esta estrategia: para el año 2017 MONDRAGON reportó 143 filiales productivas, o experiencias de globalización del proceso productivo establecido, ingresos totales por 11.936 millones de euros y 80.818 personas empleadas alrededor del mundo (MONDRAGON, 2018).

\section{El caso de Erreka Mex}

En el presente apartado se presenta el caso de estudio de Erreka Mex. Previo a la exposición de los resultados, se procede a indicar el método aplicado. 


\subsection{Método}

El presente trabajo forma parte de un estudio más amplio (Arzadun, 2012; 2015), cuyos alcances son detallados en la siguiente ficha técnica.

Tabla 2

\section{Ficha técnica}

\begin{tabular}{|c|c|}
\hline Objetivo principal & $\begin{array}{l}\text { Conocer el impacto socioeconónico de GPPE de MONDRAGON implantadas en paises en riesgo identifcados como } \\
\text { mercados objetivos, sobre la base de estrategias socialmenteresponsables e impacto económico. }\end{array}$ \\
\hline $\begin{array}{l}\text { Método de } \\
\text { investigación }\end{array}$ & Estudio de casos contemporáneo mútiple de carácter holistco (uridad de analilisis sencilla) \\
\hline Unidad de análisis & $\begin{array}{l}\text { GPPE de MONDRAGON instaladas en paises en riesgo idertificados como mercados objetivos. GPPE que pucieran } \\
\text { evaluar indicadores clave para la implantadión de la RSE en los procesos de globalización económica }\end{array}$ \\
\hline Sitio de investigación & Brasil, China, India y México \\
\hline Universo & GPPE de MONDRAGON instaladas en paises en riesgo idertifcados como mercados objetivos. \\
\hline Muestreo & Muestra lógica y teónica, selecoión par propósito (generallizadón interna, analítica) \\
\hline Muestra & Cuatro GPPE de MONDRAGON, cada una en uno de los paises en riego idertificados como mercados objetivos. \\
\hline $\begin{array}{l}\text { Instrumentos de } \\
\text { recolección de datos }\end{array}$ & $\begin{array}{l}\text { Revisión documertal, entrevistas en profundidad presenciales semi-estructuradas con preguntas abiertas y cerradas; } \\
\text { observaciones in situ; tuentes secundarias }\end{array}$ \\
\hline $\begin{array}{l}\text { Fuentes de } \\
\text { información }\end{array}$ & 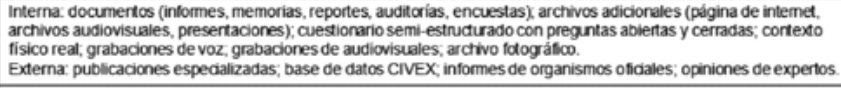 \\
\hline Informantes clave & Integrantes de la GPPE (minimo el Director General) \\
\hline $\begin{array}{l}\text { Evaluacion el rigor y } \\
\text { calidad }\end{array}$ & Validez interna y externa, fiabilidad \\
\hline $\begin{array}{l}\text { Fecha de trabajo de } \\
\text { campo }\end{array}$ & Junio de 2009 - junio de 2010. \\
\hline
\end{tabular}

Fuente: Arzadun, 2012, p.236

El trabajo global pretendió, en general, conocer cómo impacta en términos socioeconómicos la GPPE de MONDRAGON en países en riesgo considerados mercados objetivo, sobre la base de estrategias socialmente responsables e impacto económico. Por lo tanto, se busca estudiar un fenómeno complejo (la GPPE de MONDRAGON) en su contexto real (paises en riesgo considerados mercados objetivo), donde los límites entre el fenómeno y el contexto no se muestran de forma precisa (en términos socioeconómicos, sobre la base de estrategias socialmente responsables e impacto económico). Lo expuesto sienta las bases que justifican el uso del estudio de múltiples casos holístico -Tipo 3- descriptivo y explicativo como método (Yin, 1994; 2003). Concretamente se estudiaron cuatro casos, siendo uno de ellos el que aquí se expone. 
Para la evaluación del impacto socioeconómico se combinaron dos medidas. La primera consiste en la evaluación del grado en el que se alinean diversas políticas y prácticas económicas, ambientales y socialmente responsables con la estrategia empresarial (de la Torre García y Maruri Palacín, 2009; Sánchez Jiménez, 2015). Con el fin de identificar un tablero de indicadores que permitieran la evaluación de esta segunda medida, se llevó a cabo una profusa revisión de normas, estándares y herramientas, identificando las intersecciones por vertiente (social, económica y ambiental), área (buen gobierno, prácticas laborales y trabajo decente, derechos humanos, ambiente, proveedores) y dimensión (interna y externa) (Arzadun, 2015). Así, el trabajo permitió determinar un patrón de clasificación para los fines del presente estudio, lo cual se recoge en la siguiente figura.

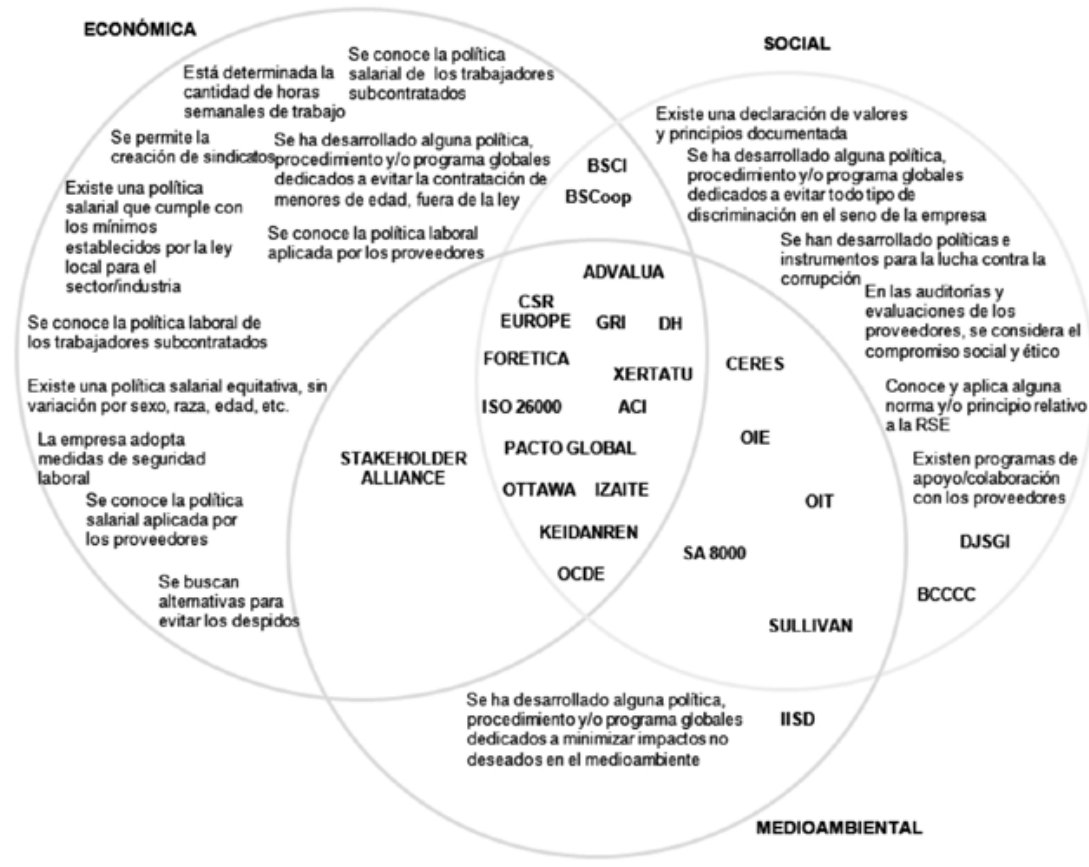

Fuente: elaboración propia

Figura 1. Referentes e indicadores clave para la implantación de la RSE en los procesos de globalización económica 
La segunda medida es el impacto económico. El modelo permite analizar y medir las relaciones existentes entre los diversos sectores de producción y consumo que integran la economía de una nación (Leontief, 1970). Es importante destacar que su aplicación no se ha limitado a los alcances macroeconómicos, sino que también penetró al ámbito de la empresa (Deller et al., 2009; Leontief, 1970). Muestra de ello son los aportes académicos y científicos que se han hecho en base a este modelo (Fontela Montes y Rueda Cantuche, 2005; Muñoz Malo, 2010; Pol, 2000; Salazar de Paz, 1983). Respecto al ámbito cooperativo en concreto, y tal como se mencionó precedentemente, se reconoce una escasa aportación (Deller et al., 2009), motivo que refuerza las posibilidades que tiene el presente trabajo de generar contribuciones.

Habiendo, hasta aquí, sentado las bases teóricas y prácticas del presente trabajo, se procede a presentar el caso de Erreka Mex.

\subsection{Erreka Mex: impacto socioeconómico}

El presente apartado está organizado en tres secciones. La primera referida al análisis del perfil y contexto de la empresa, el segundo sobre la presencia en México y el tercero relativo al impacto socioeconómico.

\subsubsection{ANÁLISIS DEL PERFIL Y CONTEXTO DE LA EMPRESA}

Guipúzcoa, provincia vasca en la que se ha desarrollado la experiencia de Erreka, vivía una intensa actividad industrial hacia la década de los sesenta. Siendo una época en la que se incrementaba y consolidaba el tejido industrial local, cuatro compañeros de una empresa de la zona dedicada a la fabricación de piezas para automóvil vislumbraron que esas organizaciones requerirían suministro de tornillería, en mayor o menor medida. De esta forma, se reunieron para dar origen a Erreka. En noviembre de 1969 ingresaron a MONDRAGON.

La proactividad y búsqueda de diversificación permitieron a la cooperativa evolucionar y desarrollarse a lo largo de sus cinco décadas de vida. Si bien el negocio de la tornillería, actual línea de Elementos de fijación, sentó las bases del inicio de actividades, progresivamente se fueron incorporando nuevos productos. De esta forma, actualmente cuenta con cuatro líneas de negocio diferenciadas:

—Elementos de Fijación;

- Plásticos;

- Automatismos;

- Puertas Automáticas. 
En el caso de los Elementos de fijación, la vocación global se desplegó prácticamente desde los inicios, comenzando con el mercado cubano al tiempo que se avanzaba en el doméstico, atendiendo a los sectores de la construcción, la minería, el ferrocarril, el agrícola y el de automoción. En la década de los ochenta inicia la exportación a mercados europeos, y una década más tarde, a Estados Unidos. Posteriormente, la empresa fue abordando nuevos y exigentes negocios, tales como el eólico. En la actualidad, la empresa es referente en este negocio, con importantes retos en materia de innovación y tecnología.

El negocio de Plásticos se emprendió en el año 1968 buscando iniciar una nueva línea distinta a tornillería a fin de abordar nuevos mercados y crear empleo. Tras una serie de desafíos y altibajos en este negocio, a comienzos del siglo XXI, la empresa comienza a abordar el mercado europeo a raíz de pedidos de sus clientes, al punto que las exportaciones representan en la actualidad el $50 \%$ de la producción. Asimismo, emprende dos experiencias de GPPE. La primera de ellas en México, caso de estudio de la presente comunicación, desde el año 2001, y la segunda en República Checa, creada en el año 2005.

Una dificultad de cobro relacionada con el negocio de Plásticos fue la causante del inicio de la línea de Automatismos en el año 1982. Ante la imposibilidad de pago por quiebra de una empresa que había efectuado un pedido de moldes para motores, se alcanzó el acuerdo de la cesión de patente. Ello, al mismo tiempo, condujo a detectar oportunidades en puertas automáticas en la década de los noventa, que se convertiría en una unidad de negocio independiente. El negocio de automatismos emprendió el abordaje del mercado externo a finales de la década de los noventa exportando a otros países de Europa y también de América del Sur. Asimismo, a partir de la GPPE en México, decidió implantar allí una delegación comercial propia para Automatismos. Por otra parte, desplegó su presencia bajo la forma de agentes comerciales en distintos países europeos y delegaciones a través de España. De todos modos, hacia el año 2006 se llegó a la conclusión de que los esfuerzos en materia de globalización requerían un mayor impulso. Ante ello, se optó por comprar una empresa que tuviera presencia en el mercado francés por ser el segundo de mayor importancia en Europa detrás de Italia, siendo que allí se encuentran los productores más importantes del continente. El acuerdo fue firmado en el año 2011.

Respecto a Puertas Automáticas, tal como se indicó precedentemente, se trata de un negocio derivado del anteriormente expuesto que se puso en marcha en el año 1994 y que cuatro años más tarde 
se definió como línea autónoma dentro de Automatismo. Poco tiempo después comienza a exportarse, con destino a Argentina. En el año 2002 se estableció como unidad de negocio independiente. Seis años más tarde, con una mayor gama de productos, se dio mayor impulso a la exportación, actividad que supone en la actualidad más del $20 \%$ de las ventas y una presencia en cerca de treinta países.

\subsubsection{Globalización eConómica: la presencia en MéXico}

La llegada a México significó la primera implantación en el exterior de Erreka, estableciendo la planta de producción en Querétaro, México, en noviembre del año 2001. Ello se vio impulsado por el pedido del cliente principal, otra cooperativa del grupo, de la Unidad de Plásticos. Si bien su cliente se encontraba en Guadalajara, se optó por Querétaro por ser una zona preparada para la recepción de empresas, pero sobre todo porque contaron con la colaboración y el apoyo de otra GPPE del grupo que les facilitó tareas de movimiento de materiales y de comercio exterior. De esta forma, se asentaron en un parque industrial colindante con otros dos, entre los cuales suman más de 200 naves de diversas dimensiones.

Tal como se mencionó previamente, Erreka tiene cuatro líneas de negocios centrales. En México, por su parte, cuenta con dos: inyección de plástico y automatismos. Habiendo abordado el mercado local con el primero, se explotaron las capacidades existentes para implementar la segunda, básicamente sobre la base de motores para puertas de garaje, puertas eléctricas, barreras de seguridad. De todos modos, en este sector hay un menor recorrido y una relevante competencia. Allí radican las principales oportunidades y amenazas identificadas en ese negocio: avanzar en el mercado a pesar de la existencia de competencia con más trayectoria. En lo que respecta a plásticos, la principal amenaza se comparte. Relativo a oportunidades, "hay muchos clientes por captar, mucho potencial en automoción. Ampliar el mercado sobre todo en la zona de la frontera donde se están instalando los grandes proveedores de automoción» (Etxaburu, 2010), aprovechando las ventajas de localización para abordar el mercado de Estados Unidos.

\subsubsection{Impacto socioeconómico de ERreKa MeX}

En el presente apartado se presentan los principales resultados del impacto socioeconómico. Para ello, primeramente, se hace referencia a los indicadores de RSE, y posteriormente al impacto económico. 
4.2.3.1. Responsabilidad económica, social y ambiental en los procesos de globalización económica

Bajo la descripción de su Proyecto Social, la empresa destaca el rol de las personas, el respeto del medioambiente, la seguridad y salud en el trabajo y la proactividad (Matz-Erreka, 2011). En cuanto a las personas, son descritas como «el valor diferencial más importante de la cooperativa» (Matz-Erreka, 2011, p.94), destacando al mismo tiempo el rol de la empresa en la creación de empleo. Bajo la noción de la necesaria implicación del colectivo para que sea posible la proyección de la empresa, fomenta el respeto mutuo, la comunicación fluida y transparente, la mejora en las condiciones laborales, el desarrollo personal y profesional. En línea con ello, se ofrece un plan de formación y evaluación continua, además de colaborar con diversos centros de investigación y formación.

Tanto el respeto al medioambiente como la seguridad y salud en el trabajo se reflejan en los valores de la empresa. "Se apuesta por promover acciones e iniciativas que contribuyan a compatibilizar el desarrollo de las actividades industriales con el respeto al medioambiente y con la seguridad y salud de las personas, procurando con ello satisfacer las necesidades y expectativas de los diversos grupos de interés» (Matz-Erreka, 2011, p.99). Para ello la empresa formula objetivos y programas internos, además de colaborar en otras iniciativas públicas o privadas.

Erreka Mex centralmente ha afianzado la dimensión interna de su RSE. "Aquí sí que se busca una RSE de empleo», de acuerdo con Etxaburu (2010), cuestión que la empresa atiende desde diferentes perspectivas. En este sentido, se identifica al salario como una variable que incide en la rotación de personas. "Los trabajadores suelen aprovechar el comienzo del año para cambiar de empresa» (Etxaburu, 2010). Erreka Mex ha adoptado medidas tendientes a contrarrestar la búsqueda laboral por motivos económicos con la intención de lograr una plantilla estable. Asimismo, se procura transmitir una visión de largo plazo, de oportunidades de crecimiento. Sin embargo, de acuerdo con la actividad desempeñada, "el salario se convierte en un factor relevante de retención, aunque no sea el principal».

La tabla siguiente sintetiza aspectos en los que la empresa ha comenzado a trabajar. 
Tabla 3

\section{Principales indicadores de RSE: Erreka Mex}

\begin{tabular}{|l|c|}
\hline \multicolumn{1}{|c|}{ PRINCIPALES INDICADORES } & UIErreka Mex \\
\hline Declaración de valores y principios documentada & \\
\hline Rechazo del trabajo forzoso & $\checkmark$ \\
\hline Libertad de asociación y negociación colectiva & $\checkmark$ \\
\hline Política salarial: cumplimiento de la ley & $\checkmark$ \\
\hline Política salarial equitativa & $\checkmark$ \\
\hline Condiciones laborales: asegurar buenas condiciones de trabajo, salud y seguridad & $\checkmark$ \\
\hline Políticas para evitar despidos y mantener el empleo & $\checkmark$ \\
\hline Inclusión de los DDHH & $\checkmark$ \\
\hline Rechazo del trabajo infantil & $\checkmark$ \\
\hline Protección del Medioambiente & $\checkmark$ \\
\hline Lucha contra la corrupción & \\
\hline
\end{tabular}

Fuente: Arzadun, 2012, p.387.

\subsubsection{Impacto económico}

La actividad económica desarrollada por uma empresa em um período determinado genera uma serie de efectos en la economía (directo, indirecto e inducido) que en su conjunto se traducen en un nivel dado de creación de puestos de trabajo y PIB. Para el caso de Erreka Mex, a partir de las matrices insumo producto de Brasil, creó 59 puestos de trabajo con la distribución que se señala a continuación.

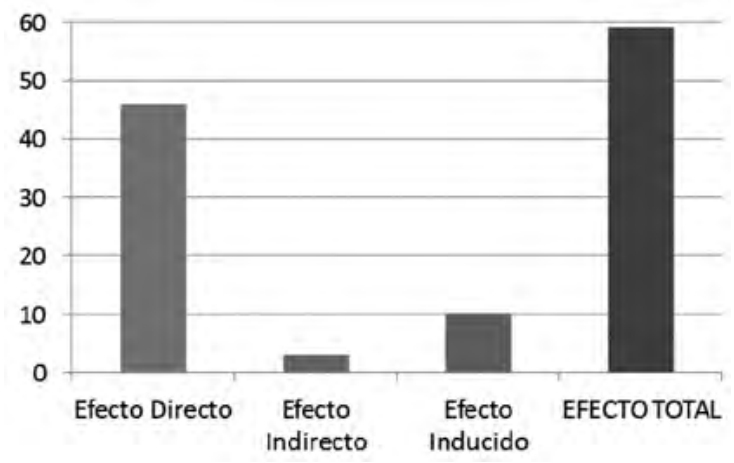

Fuente: elaboración propia.

Gráfico 2. Impacto Económico de Erreka Mex: generación de puestos de trabajo 
Además de los puestos de trabajo creados, los alcances del impacto económico se completan con los aportes que la empresa realiza en términos de generación de PIB. En este sentido, el aporte de Erreka Mex supera un millón cuatrocientos mil Euros.

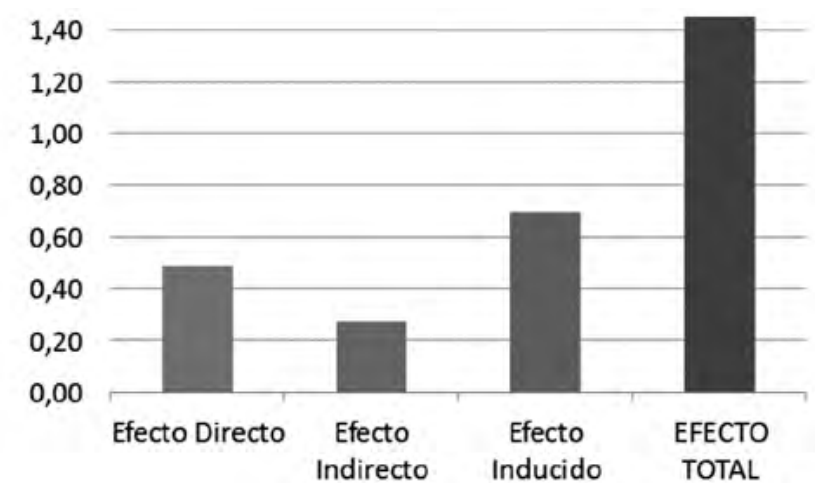

Fuente: elaboración propia.

Gráfico 3. Impacto Económico de Erreka Mex: generación de PIB (en millones de Euros).

Seguidamente se detalla cuáles han sido los pasos seguidos para calcular estas cifras. Los cálculos se asientan en las TIO de México obtenidas a partir de OCDE.StatExtracts, cuya última actualización corresponde a noviembre de 2010 aunque la selección es de mediados de 2000.

Tabla 4

TIO México, en millones de euros

\begin{tabular}{|l|c|c|c|c|}
\cline { 2 - 5 } \multicolumn{1}{c|}{} & C25 & C27 & C28 & Resto sectores \\
\hline C25 & 44,7194 & 5,0141 & 16,8433 & 1100,4193 \\
\hline C27 & 19,2766 & 425,8077 & 200,1411 & 1164,8081 \\
\hline C28 & 14,8273 & 9,7833 & 60,1744 & 774,4864 \\
\hline Resto sectores & 473,2318 & 539,5647 & 273,4552 & 32729,7132 \\
\hline \hline PROD & 822,6923 & 1551,7925 & 845,6971 & 86882,7698 \\
\hline TAXS & 552,0552 & 980,1699 & 550,6140 & 35769,4269 \\
\hline VALU & 268,5130 & 560,4889 & 292,6124 & 50820,6878 \\
\hline GOPS & 143,1026 & 420,6709 & 158,6035 & 31819,0649 \\
\hline LABR & 121,9225 & 137,0502 & 130,3957 & 16800,6073 \\
\hline OTXS & 3,4879 & 2,7679 & 3,6132 & 2201,0157 \\
\hline
\end{tabular}

Fuente: elaboración propia a partir de las TIO de México, OCDE.StatExtracts. 
Las variables recogidas por la TIO previa son las que se detallan a continuación:

Tabla 5

Sectores e inputs primarios

\begin{tabular}{|l|l|}
\hline C25 & Goma y productos plásticos \\
\hline C27 & Metales básicos \\
\hline C28 & Productos de metal fabricados excepto maquinaria y equipos \\
\hline PROD & Output neto (Producción) a precios básicos \\
\hline TAXS & Impuestos menos subsidios sobre productos \\
\hline VALU & Valor agregado a precios básicos \\
\hline GOPS & Excedente bruto de explotación \\
\hline LABR & Compensación a empleados \\
\hline OTXS & Otros impuestos menos subsidios a la producción \\
\hline
\end{tabular}

Fuente: elaboración propia a partir de las TIO de México, OCDE.StatExtracts.

A partir de esos datos, se delinea la Matriz Intermedia con los sectores vinculados con la producción de Erreka Mex.

Tabla 6

TIO México: matriz Intermedia

\begin{tabular}{|l|c|c|c|c|}
\hline \multicolumn{1}{|c|}{} & C25 & C27 & C28 & Resto sectores \\
\hline C25 & 44,7194 & 5,0141 & 16,8433 & 1100,4193 \\
\hline C27 & 19,2766 & 425,8077 & 200,1411 & 1164,8081 \\
\hline C28 & 14,8273 & 9,7833 & 60,1744 & 774,4864 \\
\hline Resto sectores & 473,2318 & 539,5647 & 273,4552 & 32729,7132 \\
\hline
\end{tabular}

Fuente: elaboración propia a partir de las TIO de México, OCDE.StatExtracts.

La proporción entre la Matriz Intermedia y la producción, da como resultado la Matriz de Coeficientes Verticales (A), estableciéndose las relaciones entre cada uno de los consumos intermedios de las actividades y el total de la producción. 
Tabla 7

TIO México: matriz de Coeficientes Verticales (A)

\begin{tabular}{|l|c|c|c|c|}
\cline { 2 - 5 } \multicolumn{1}{c|}{} & $\mathrm{C} 25$ & $\mathrm{C} 27$ & $\mathrm{C} 28$ & Resto sectores \\
\hline $\mathrm{C} 25$ & 0,0043 & 0,0003 & 0,0016 & 0,0010 \\
\hline $\mathrm{C} 27$ & 0,0018 & 0,0215 & 0,0185 & 0,0010 \\
\hline C28 & 0,0014 & 0,0005 & 0,0056 & 0,0007 \\
\hline Resto sectores & 0,0450 & 0,0272 & 0,0253 & 0,0295 \\
\hline
\end{tabular}

Fuente: elaboración propia a partir de las TIO de México, OCDE.StatExtracts.

Tras la elaboración de una Matriz Identidad (I), ésta es restada por la Matriz de Coeficientes Verticales A. De esta manera se obtiene la matriz de Leontief. La matriz de multiplicadores o matriz inversa de Leontief se obtiene invirtiendo la matriz (I-A).

Tabla 8

TIO México: Matriz Inversa de Leontief

\begin{tabular}{|l|c|c|c|c|}
\hline & C25 & C27 & C28 & Resto sectores \\
\hline C25 & 0,0839 & 0,0012 & 0,0027 & 0,0018 \\
\hline C27 & 0,0436 & 0,9514 & 0,2520 & 0,0029 \\
\hline C28 & 0,0212 & 0,0119 & 0,7394 & 0,0013 \\
\hline Resto sectores & 0,0815 & 0,0629 & 0,0628 & 0,1294 \\
\hline
\end{tabular}

Fuente: elaboración propia a partir de las TIO de México, OCDE.StatExtracts, de acuerdo con el modelo de Leontief (1970).

Los Multiplicadores de la Producción se determinan como la sumatoria de las columnas de la Matriz Inversa de Leontief. Y los Coeficientes de Relación con la Producción se calculan a partir de las magnitudes de valor agregado bruto, empleo e impuestos de la TIO, para finalmente calcular los multiplicadores que incluyen el efecto indirecto como el producto entre la Matriz Inversa de Leontief y los Coeficientes de Relación con la Producción. A continuación, se detallan los resultados, para el PIB y los Puestos de trabajo. 
Tabla 9

Coeficientes y multiplicadores resultantes. Efecto directo e indirecto

\begin{tabular}{|c|c|c|c|c|c|}
\hline & & $\mathrm{C} 25$ & $\mathrm{C} 27$ & $\mathrm{C} 28$ & Resto sectores \\
\hline \multicolumn{2}{|c|}{ Multiplicador de la producción } & 0,1728 & 0,1750 & 0,1797 & 0,1354 \\
\hline \multirow{3}{*}{$\begin{array}{l}\text { Coeficientes } \\
\text { relacionados } \\
\text { con la } \\
\text { producción }\end{array}$} & $\mathrm{PIB}$ & 0,0780 & 0,0777 & 0,0780 & 0,0780 \\
\hline & PdT, por millón de euros & 0,0116 & 0,0069 & 0,0121 & 0,0151 \\
\hline & $\mathrm{PdT}$, por euro & $1,159 \mathrm{E}-08$ & 6,910 E-09 & $1,206 \mathrm{E}-08$ & $1,513 \mathrm{E}-08$ \\
\hline \multirow{3}{*}{$\begin{array}{l}\text { Resto de } \\
\text { multiplicadores }\end{array}$} & $\mathrm{PIB}$ & 0,1723 & 0,1740 & 0,1790 & 0,1349 \\
\hline & PdT, por millón de euros & 0,0290 & 0,0222 & 0,0282 & 0,0257 \\
\hline & PdT, por euro & $2,901 \mathrm{E}-08$ & $2,223 \mathrm{E}-08$ & $2,824 \mathrm{E}-08$ & $2,574 \mathrm{E}-08$ \\
\hline
\end{tabular}

Fuente: elaboración propia a partir del modelo de Leontief (1970).

Los pasos seguidos para el análisis de Efecto Inducido que genera la actividad de Erreka Mex requieren la incorporación de las Familias como sector endógeno. Para ello se incorpora su consumo estimado y el monto de Sueldos y Salarios brutos deducidos los pagos de impuestos. PROD se calcula como los Sueldos y Salarios brutos deducidos los pagos de impuestos más las rentas recibidas del exterior.

La Matriz Intermedia Ampliada ahora tendrá un sector adicional. Seguidamente se procede a efectuar los cálculos antes detallados: se elabora una Matriz Identidad que se corresponda a las dimensiones de la Matriz Intermedia Ampliada. Se procede a efectuar la diferencia (I-A) para luego invertirla y obtener la Matriz Invertida de Leontief.

Tabla 10

Matriz Inversa de Leontief con Sector Familias

\begin{tabular}{|l|c|c|c|c|c|}
\cline { 2 - 6 } \multicolumn{1}{c|}{} & C25 & C27 & C28 & Resto sectores & Sector familia \\
\hline C25 & 0,0887 & 0,0065 & 0,0076 & 0,0067 & 0,0139 \\
\hline C27 & 0,0121 & 0,1172 & 0,0362 & 0,0102 & 0,0205 \\
\hline C28 & 0,0063 & 0,0056 & 0,0890 & 0,0053 & 0,0112 \\
\hline Resto sectores & 0,3797 & 0,3890 & 0,3656 & 0,4363 & 0,8594 \\
\hline Sector familia & 0,0918 & 0,1003 & 0,0932 & 0,0944 & 0,2644 \\
\hline
\end{tabular}

Fuente: elaboración propia a partir de las TIO de México, OCDE.StatExtracts, de acuerdo con el modelo de Leontief (1970).

Así, utilizando la relación existente entre Multiplicador de Producción y Multiplicadores de PIB y Empleo obtenidos en los cálculos prece- 
dentes, se arriba a los multiplicadores que incluyen el Efecto Inducido, detallados en la siguiente tabla.

Tabla 11

Multiplicadores de la producción y resto de multiplicadores

\begin{tabular}{|c|c|c|c|c|c|}
\hline & $\mathrm{C} 25$ & $\mathrm{C} 27$ & $\mathrm{C} 28$ & Resto sectores & Sector familia \\
\hline \multicolumn{6}{|c|}{ Multiplicador Producción } \\
\hline $\begin{array}{l}\text { Incluyendo sector } \\
\text { familias }\end{array}$ & 0,5786 & 0,6187 & 0,5917 & 0,5529 & 1,1695 \\
\hline $\begin{array}{l}\text { Sin incluir sector } \\
\text { familias }\end{array}$ & 0,4868 & 0,5183 & 0,4985 & 0,4585 & 0,9050 \\
\hline \multicolumn{6}{|l|}{ Resto de multiplicadores } \\
\hline Producción sin familias & 0,4868 & 0,5183 & 0,4985 & 0,4585 & 0,9050 \\
\hline $\begin{array}{l}\text { Producción } \\
\text { (meD+melndi) }\end{array}$ & 0,1728 & 0,1750 & 0,1797 & 0,1354 & \\
\hline PIB (meD+melndi) & 0,1723 & 0,1740 & 0,1790 & 0,1349 & \\
\hline PdT (meD+melndi) & 0,0290 & 0,0222 & 0,0282 & 0,0257 & \\
\hline $\begin{array}{l}\text { PIB } \\
(m e D+m e l n d i+m e l n d u)\end{array}$ & 0,4853 & 0,5154 & 0,4966 & 0,4569 & \\
\hline $\begin{array}{l}\mathrm{PdT} \\
(\mathrm{meD}+\text { melndi+melndu })\end{array}$ & 0,0817 & 0,0658 & 0,0784 & 0,0872 & \\
\hline
\end{tabular}

Fuente: elaboración propia a partir del modelo de Leontief (1970).

Los sucesivos pasos efectuados permiten entonces definir los multiplicadores asociados a la actividad de Erreka Mex. La siguiente tabla recoge los meD, melndi y melndu para cada uno de los sectores diferenciando entre PIB y Puestos de trabajo.

Tabla 12

\section{Erreka Mex: multiplicadores por sector y Efectos Directo, Indirecto e Inducido}

\begin{tabular}{|c|c|c|c|c|c|c|c|c|}
\hline & \multicolumn{2}{|c|}{$\mathrm{C} 24$} & \multicolumn{2}{|c|}{$\mathrm{C} 26$} & \multicolumn{2}{|c|}{$\mathrm{C} 28$} & \multicolumn{2}{|c|}{ Resto sectores } \\
\hline & PIB & PdT & PIB & PdT & PIB & PdT & PIB & PdT \\
\hline $\mathrm{meD}$ & 0,0067 & 0,0891 & 0,0072 & 0,1701 & 0,0076 & 0,1725 & 0,0107 & 0,1110 \\
\hline melndi & 0,0525 & 0,0124 & 0,0595 & 0,0155 & 0,0591 & 0,0140 & 0,0697 & 0,0220 \\
\hline melndu & 0,0136 & 0,0037 & 0,0130 & 0,0039 & 0,0120 & 0,0039 & 0,0092 & 0,0029 \\
\hline
\end{tabular}

Fuente: elaboración propia a partir del modelo de Leontief (1970). 
Recapitulando, conociendo las ganancias percibidas, los salarios e impuestos pagados, el número de puestos de trabajo creados y la remuneración a otros factores, según el cálculo del PIB por el método de la distribución o del ingreso, es posible determinar el efecto directo generado por la empresa. Asimismo, el cálculo de los multiplicadores permite analizar las concatenaciones que aquel impacto directo genera en la economía por medio de los efectos indirecto e inducido. Para ello, adicionalmente se requiere obtener datos acerca del perfil de gasto en input por parte de la empresa, así como el patrón de consumo medio de las familias residentes. A partir de esta información y los multiplicadores obtenidos, se calcula el impacto económico de Erreka Mex. Como puede observarse por los valores anteriormente señalados, y dada la composición de gasto intersectorial y en salarios de la empresa bajo análisis, el impacto inducido supera al indirecto. En este caso, además de la menor relevancia relativa de los salarios, estos resultados reflejan el hecho de que el mayor volumen de aprovisionamiento de la empresa no es local porque la adquisición de materia prima se realiza fuera de México, según indicaciones de sus propios clientes. Por lo tanto, los resultados producto de las concatenaciones intersectoriales son inferiores a las acaecidas por incremento de la renta.

\section{Discusión}

Las estrategias de globalización en el sector cooperativo no están exentas de controversias. Entonces, para formar criterios relativamente objetivos respecto a la incidencia de tales estrategias es preciso conocer sus efectos. En este sentido, el presente trabajo brinda insumos originales para evaluar el impacto de la globalización de procesos productivos establecido, tanto en términos estrictamente económicos como en términos socioeconómicos a partir de estrategias socialmente responsables.

Analizando los principales indicadores de RSE en los procesos de globalización económica, se observan mayores aspectos considerados estratégicos en la dimensión interna respecto a la externa. En este sentido, los elementos clave sobre los que parece converger toda acción es la persona, así como el desarrollo de sólidos y estables equipos de trabajo locales. Por ello se impulsa escenarios propensos a la cohesión, la participación, el desarrollo de un sentido de pertenencia, la inexistencia de conflictividad, y sobre todo, la admisión de todo ello como una característica inherente de la empresa. 
En cuanto a la medición del impacto económico, permitió conocer los efectos generados interna y externamente en materia de puestos de trabajo y de ingresos. Más aún, a través del conocimiento desglosado del efecto indirecto e inducido fue posible identificar la incidencia de la empresa en cada uno de ellos. La actividad desarrollada por una empresa genera una sucesión de impactos encadenados que interactúan en el sistema de forma iterativa y dinámica. De esta forma, al final del proceso, el impulso inicial genera un efecto multiplicador y renta sobre el conjunto del sistema económico. Así, Erreka Mex presenta un desarrollo de actividad tal que el impacto inducido supera al indirecto. Los efectos indirectos generan cambios en las transacciones interindustriales cuando las industrias proveedoras responden a incrementos en la demanda de industrias directamente afectadas, mientras que los efectos inducidos impulsan variaciones en el gasto local resultante de incremento de la renta de los hogares. El mayor peso relativo del efecto inducido frente al indirecto, subyace el escaso nivel de aprovisionamiento de origen local. Por las características de su producción, la materia prima es mayormente adquirida a proveedores de origen europeo o estadounidense. Más aún, por lo general es el cliente el que marca las pautas de compra. De esta forma, el propio esquema de compra limita las concatenaciones intersectoriales, lo cual explica la mayor relevancia del efecto inducido.

Los resultados reseñados ponen en relieve la existencia de múltiples relaciones con heterogéneos agentes, y positivos efectos. Ahora bien, es igualmente importante reconocer los desafíos referidos a realzar las características diferenciales del sector cooperativo, apartarse de concepciones escasamente apropiadas, y apropiarse de particularidades que evidentemente despiertan interés en el resto de las organizaciones. Todo ello no con el objetivo de desestimular a otras entidades en el camino de la RSE, sino por destacar su rol pionero y tractor además de dar respuestas a las expectativas que sus cualidades intrínsecas generan. Porque, así como no puede negarse que diversas empresas del sector privado tradicional han progresado en materia de RSE, tampoco puede ocultarse el hecho de que la propia idiosincrasia cooperativa provoca que se espere el alineamiento de sus objetivos con los de la triple vertiente $y$, por ende, la consideración y actitud activa con sus diversos grupos de interés, allí donde se encuentre. En este sentido, se aprecia que la presente investigación ha generado aportes en los vacíos identificados conocimiento del impacto socioeconómico generado por estrategias de GPPE. Ello, a su vez, abre una serie de futuras líneas de investigación que pudieran continuar fortaleciendo estos hallazgos. Pudieran devenir nuevos estudios que robustezcan la validez externa del 
modelo aquí propuesto, al mismo tiempo que amplían la base de datos existente incorporando otros casos, sean éstos del entorno MONDRAGON o no. Igualmente se podría avanzar en los alcances del impacto económico estudiando los grados de dependencia y encadenamientos productivos a partir de los coeficientes de arrastre hacia adelante y hacia atrás.

Se reconoce que son múltiples los desafíos a los que se enfrenta el sector cooperativo, en particular, y empresarial, en general, ante los retos de la globalización económica. Habiendo generado aportes en esa materia, se espera igualmente que la identificación de líneas futuras continúe desplegando estudios en las diferentes aristas que ello supone.

\section{Referencias bibliográficas}

AdDA, J. (1999) Globalización de la economía. Orígenes y desafíos, Madrid: Sequitur.

Alonso, J. y Donoso, V. (Ed.) (1994) Competitividad de la empresa exportadora española, Madrid: ICEX.

ARZADUn, P. (2012) Estudio empírico sobre globalización del proceso productivo establecido de Mondragón y su impacto socioeconómico. Confluencia entre globalización, RSE, empresa y desarrollo (tesis doctoral). Oñati: Facultad de Empresariales de la Universidad de Mondragón.

Arzadun, P. (2015) Globalización del proceso productivo establecido y su impacto socioeconómico. El caso de Orkli Kunshan S. Coop. en China, CIRIEC-España, Revista de Economía Pública, Social y Cooperativa, 83, pp. 169-199.

BerTULLo, J (2007) El cooperativismo en la sociedad global ¿pervivencia de una utopía o forma emergente de organizar la renta del capital?, en Radrigán Rubio, M., (Coord.), El rol de las cooperativas en un mundo globalizado, Québec: IRECUS, pp. 90-109.

Cadarso Vecina, M., López Santiago, L. y Tobarra Gómez, M. (2007) Especialización vertical, outsourcing, e inversión directa en la industria española, Revista de Economía Mundial, 16, pp. 27-55.

Cancelo, A. (1996) El Plan estratégico corporativo de internacionalización de MCC, Boletín de la Asociación Internacional de Derecho Cooperativo, 25, pp. 27-31.

CESE - Comité Económico y Social Europeo (2005) Alcance y efectos de la deslocalización de empresas, CESE dictamen de iniciativa 851/2005, http://eescopinions.eesc.europa.eu/EESCopinionDocument.aspx?identifier=ceslccmil ccmi014lces851-2005_ac.doc\&language=ESv, consultado el 8 de junio de 2018. 
Chamberlin E. H. (1933) The theory of monopolistic competition, Cambridge: Harvard University Press

De Castro Sanz, M. (2005) La responsabilidad social de las empresas, o un nuevo concepto de empresa. CIRIEC - España, Revista de Economía Pública, Social y Cooperativa, 54, pp. 29-51.

De La DehesA, G. (2000) Comprendiendo la globalización, Madrid: Alianza Editorial.

De la Torre García, C. y Maruri Palacín, I. (2009) La Responsabilidad Social de Género en la Empresa. Un valor emergente del management empresarial, Madrid: Cinca.

Deller, S., Hoyt, A., Hueth, B. y Sundaram-Stukel, R. (2009) Research on the Economic Impact of Cooperatives, Wisconsin: University of Wisconsin Center for Cooperatives.

EtXABuRu, M. (2010) Comunicación personal. Entrevista individual de 2 horas realizada en las instalaciones de Erreka Mex en Querétaro, México, en junio de 2010.

FisCHeR, S. y DoRnBusCH, R. (1985) Economía, México: McGraw-Hill.

Frank, G. (1974) El desarrollo del subdesarrollo, Bilbao: Zero.

Fonseca, J. y Martínez González-Tablas, Á. (2008) Economía Política de la globalización y su crisis, en La Globalización en el siglo XXI: retos y dilemas, Zamudio: Argia Grafika. pp. 33-54.

Fontela Montes, E. y Rueda Cantuche, J. (2005) Modelos Input-Output y análisis probabilístico de impacto cruzado mediante escenarios, Revista de Economía Mundial, 13, pp. 99-112.

García ZABALA, A. (2005) La inversión extranjera directa y la empresa transnacional en la era de la globalización, en Etxeberria, X., García Zabala, A., y Royo, S., coord., Responsabilidad y ética de las empresas inversoras en los países empobrecidos, Bilbao: Bakeaz; Emaús Fundación Social, pp. 45-86.

Gómez García, J. (2015) El modelo cooperativo y el nuevo enfoque del desarrollo territorial: elementos de convergencias y potenciales sinergias, Deusto Estudios Cooperativos, 6, pp. $79-114$.

GRUBEL y LLOYD (1975) Intra-industry trade: the theory and measurement of international trade in differentiated products, Londres: Macmillan.

Harrod, R. (1939) An essay in dynamic theory, Economical Journal, 49, pp.14-33.

Helpman, E., Melitz, M. y Yeaple, S. (2004) Export versus FDI with heterogeneous firms, American economic review, 94, 1, pp. $300-316$.

Herrasti, J. (2010) Comunicación personal. Entrevista individual de 2 horas realizada en el Polo de Innovación Garaia en Arrasate, País Vasco, en noviembre de 2010.

HiRsChman, A. (1958) The Strategy of Economic Development, Connecticut: Yale University Press.

HYMER, S. (1976) The international operations of national firms: a study of direct foreign investment, Cambridge: Massachusetts Institute of Technology. Originariamente presentada como la tesis del autor, Massachusetts Institute of Technology, 1960. 
IZQUIERDO AlBeRT, C. (2007) La globalización neoliberal. Tendencias fundamentales. Impacto en el cooperativismo, en Radrigán Rubio, M. (Coord.), El rol de las cooperativas en un mundo globalizado, Québec: IRECUS, pp. 40-66.

KAPLAN DE DRIMER, A. (1996) Las mutaciones estructurales de las cooperativas autorizadas o propuestas en algunos países, ¿permitirán preservar la naturaleza cooperativa y el interés general de sus miembros?, en Monnier, L. et al. Cambios estructurales e interés general: hacia nuevos paradigmas para la economía, social y cooperativa, Valencia: CIRIEC, pp. 198-216.

KARNANI, A (2007) Employment, not microcredit, is the solution. Ross School of Business Working Paper Series, w.p. 1065, Michigan: University of Michigan.

KosACOFF, B. (2009) Especialización productiva, transnacionales y desarrollo económico en la argentina, en Ministerio de Trabajo, Empleo y Seguridad Social - MTESS, RSE y trabajo decente en la argentina (1. ${ }^{\circ}$ ed.), Buenos Aires: autor, pp. 65-97.

KRUgman, P. y ObSTFeld, M. (1999) Economía internacional. Teoría y práctica (4. ${ }^{\circ}$ ed.), Madrid: McGraw-Hill.

LALL, S. (1993) Transnational corporations and economic development, en Naciones Unidas. División de Corporaciones Transnacionales y Dirección, Transnational corporations and economic development, Kentucky: Routledge, pp.44-65.

Lara Gómez, G. y Rico Hernández, A. (2007) Cooperativas de producción y outsourcing, en Radrigán Rubio, M. (Coord) (2007), El rol de las cooperativas en un mundo globalizado, Québec: IRECUS, pp. 161-181.

Llamosas Trápaga, A. (2018) La Economía Social. Una vía para la creación de un empleo estable y de calidad, Deusto Estudios Cooperativos, 10, pp. 31-46.

LEONTIEF, W. (1970) Input - Output Economics, Oxford University Press. Versión en castellano, Barcelona: Editorial Gustavo Gili.

Martínez González-TABlAS, A. (2004) La dimensión empresarial en la fase actual del proceso de globalización, Economía Crítica, 3, pp. 37-68.

Matz-ERREKA (2011) Informe anual 2010, Matz-Erreka: Guipúzcoa.

Mendizabal, A. y ERrasti, A. (2006) Aspectos económicos y sociales de las deslocalizaciones productivas, Lan Harremanak Especial/Ale Berezia 2006, pp. 167-192.

MondRAGON (2018) Informe anual 2017, https://www.mondragon-corporation. com/informe-anual-2018/assets/doc/INFORME-ANUAL-2017.pdf, consultado el 7 de agosto de 2018.

Monzón, J. (2012) Las cooperativas ante la globalización: magnitudes, actividades y tenencias, Ekonomiaz, 79, pp. 12-29.

MuÑos Malo, J. (2010) Evaluación del impacto sobre la ocupación total catalana de la crisis inmobiliaria a partir de una simulación con las tablas inputoutput de Cataluña, XVII Jornadas de Estadística de las Comunidades Autónomas, pp.1-11.

MyrdaL, G. (1957) Teoría económica y regiones subdesarrolladas, México D.F: Fondo de Cultura Económica.

Ohmae, K. (2005) The next global stage, Nueva Delhi: Pearson. 
OIT - Oficina Internacional de Trabajo (1998a) Seminário Internacional: Emprego e Desenvolvimento Tecnológico no Mercosul, Florianópolis, Brasil 29 a 30 de Septiembre de 1998, http://www.ilo.org/public/spanish/region/ ampro/cinterfor/temas/worker/doc/otros/i/iii/index.htm, consultado el 3 de julio de 2018.

PITELIS, C. (2006) A learning-based perspective of the multinational Enterprise, Judge Business School, University of Cambridge, Working Paper Series, 19, 2006, pp. 1-14.

PoL, R. (2000) Efecto Inductor de MCC en la Economía del País Vasco. Proyecto final de MBA. Otalora - Centro de Desarrollo Directivo y Cooperativo de MONDRAGON.

Porter, M y Kramer, R (2006) Strategy \& Society. The link between competitive advantage and Corporate Social Responsibility, Harvard Business Review, pp.1-15.

Rubert Adelantado, G. y Uribe-Echeverría, A. (2002) La especialización vertical en el comercio internacional de España, Información Comercial Española, ICE: Revista de economía, 802, pp. 117-128.

Salazar de Paz, A. (1983) Planeamiento Financiero Input-Output en Microeconomia (Caso Practico en una Fábrica Peruana. Tesis doctoral. Universidad Complutense de Madrid.

SALAZAR-XIRINACHS, J. (2008) Las multinacionales y las prácticas socialmente responsables, Trabajo, 62, pp. 4-12.

SÁNCHEZ JIMÉNEZ, V. (2015) La redefinición del papel de la empresa en la sociedad, BARATARIA Revista Castellano - Manchega de Ciencias Sociales, 20, pp. 129-145

SomAVIA, J. (1999) Memoria del Director General: Trabajo Decente. 87. ${ }^{a}$ reunión de la Conferencia Internacional del Trabajo. Oficina Internacional del Trabajo, Ginebra, http://www.oit.org/public/spanish/standards/relm/ilc/ ilc87/rep-i.htm, consultado el 14 de septiembre de 2009.

StIGLITZ, J. (2002) El malestar en la globalización, Madrid: Taurus.

Solow, R. (1956) A contribution to the theory of Economic Growth, Quarterly Journal of Economics, 70, 1, pp.65-94.

SWAN, T. (1956) Economic growth and capital accumulation, Economic record, 32 , pp. 334-361.

Tugores Ques, J. (2006) Economía Internacional. Globalización e integración regional, Madrid: McGraw-Hill.

YIN, R. (1994) Case Study Research (2. ${ }^{\circ}$ ed.), Thousand Oaks, CA: Sage Publishing. YIN, R. (2003) Case Study Research (3. ed.), Thousand Oaks, CA: Sage Publishing. 